\title{
Evaluation of Endotracheal Tube Cuff Pressure in Laparoscopic Cholecystectomy and Postoperative Sore Throat
}

\author{
Gajal Lakhe, ${ }^{1}$ Surendra Mohan Sharma ${ }^{1}$ \\ 1Department of Anesthesia, Manipal College of Medical Sciences, Phulbari 11, Pokhara, Nepal.
}

\begin{abstract}
Background: The use of nitrous oxide and carboperitoneum in laparoscopic cholecystectomy lead to increase in endotracheal tube cuff pressure. It may impair tracheal mucosal perfusion with subsequent tracheal damage. The purpose of this study was to evaluate cuff pressure and incidence of post-operative sore throat in patients undergoing laparoscopic cholecystectomy.

Methods: In this prospective observational study, 128 patients aged 18-65 years of American Society of Anesthesiologist physical status I and II undergoing laparoscopic cholecystectomy were enrolled and allocated alternately into two groups, Study Group (Maintenance of anesthesia with sevoflurane 1-2\%, oxygen/nitrous oxide mixture; 40/60), Control Group (Maintenance of anesthesia with sevoflurane 1-2\%, oxygen/air mixture; 40/60) were analysed and comapared. Each group contained 64 patients. Aneroid manometer was used to monitor cuff pressure. Volume of air used to inflate the cuff, baseline cuff pressure, comparison of intraoperative cuff pressure and incidence of postoperative sore throat were measured.

Results: The study results demonstrated higher cuff pressure in study group at all times after the creation of carboperitoneum $(\mathrm{p}=0.00)$ with increased incidence of sore throat $(\mathrm{p}=0.004)$.

Conclusions: Increase in endotracheal tube cuff pressure was noted with the use of nitrous oxide in laparoscopic cholecystectomy with subsequent post-operative airway complication. Monitoring of cuff pressure is simple, noninvasive and efficient way of achieving therapeutic cuff pressure of $20-30 \mathrm{~cm}$ of $\mathrm{H} 2 \mathrm{O}$ and thus recommends its use.

Keywords: Carboperitoneum; cuff pressure; nitrous oxide; sore throat.
\end{abstract}

\section{INTRODUCTION}

Carboperitoneum created at $10-15 \mathrm{~mm}$ of $\mathrm{Hg}$ for laparoscopic cholecystectomy distends the peritoneal cavity and increases intra-abdominal pressure. This pressure gets transmitted to thoracic cage which raises endotracheal tube (ETT) cuff pressure and use of nitrous oxide further add to it. ${ }^{1,2}$ Cuff pressure of 20-30 $\mathrm{cm}$ of $\mathrm{H} 2 \mathrm{O}$ is recommended which is seldom measured and palpation of pilot balloon is not the definite way of assessment. This study was planned to evaluate cuff pressure in laparoscopic cholecystectomy and postoperative airway complication.

\section{METHODS}

This prospective, observational study was carried out in the Department of Anesthesia of Manipal
College of Medical Sciences from May 2015 to April 2016 after obtaining clearance from the institutional research committee and written informed consent from the patients. Patients undergoing laparoscopic cholecystectomy were enrolled in the study. Patients with ongoing upper respiratory tract infection, more than two attempts of intubation, difficult airway, nasogastric tube left in situ, oral airway, throat pack and lubricating jelly on ETT were excluded from the study. Total of 128 adult patients of American Society of Anesthesiologist (ASA) physical status I and II, aged 18-65 years were enrolled.The patients were allocated alternately to one of the 2 groups: Study Group (Maintenance of anesthesia with sevoflurane $1-2 \%$, oxygen/nitrous oxide mixture; 40/60), Control Group (Maintenance of anesthesia with sevoflurane 1-2\%, oxygen/air mixture; 40/60). Each group contained 64 patients. 
Independent t-test or Mann Whitney $U$ test was used for quantitative variables as appropriate, chi square for categorical variable and one-way analysis of variance (ANOVA) for repeated measures of cuff pressure. $P$ value of $\leq 0.05$ was considered significant. Data was analyzed using SPSS (The Statistical Package for Social Sciences) version 20.0 software.

The patients were premedicated with oral alprazolam $0.5 \mathrm{mg}$ on night before and 2 hours prior to surgery. Patients were shifted to the operation theatre and ASA standard monitors attached. After preoxygenation for 3 minutes, anesthesia was induced with fentanyl 1-2 $\mu \mathrm{g} /$ $\mathrm{kg}$ and propofol 2-2.5 mg/kg iv. Neuromuscular blockade was achieved with $0.1 \mathrm{mg} / \mathrm{kg}$ of vecuronium. After 4 minutes of assisted ventilation patients were intubated using size 7 or $8 \mathrm{~mm}$ internal diameter ETT for female and male respectively. Romson's ETT with high residual volume and low pressure cuff was used. All intubations were done by single experienced anesthesiologist. After endotracheal intubation gastric decompression was done by one time passage of orogastric tube. It was not left in situ during the surgical procedure as it could lead to post-operative sore throat.The ETT cuff was inflated with air using $10 \mathrm{ml}$ syringe by anesthesia assistant as this is the common practice in our institute. Volume of air used to inflate the cuff and the resultant baseline cuff pressure was measured. Pilot balloon was connected to the aneroid manometer to measure cuff pressure (Figure1). Baseline cuff pressure equal to, more than or less than $25 \mathrm{~cm}$ of $\mathrm{H} 2 \mathrm{O}$ was recorded. Air was then added or removed with $2 \mathrm{ml}$ syringe as required to maintain the initial cuff pressure of $25 \mathrm{~cm}$ of $\mathrm{H} 2 \mathrm{O}$. Cuff pressure was monitored continuously throughout the procedure and values recorded every 5 minutes. Changes in the cuff pressure with the onset of carboperitoneum and reverse-trendelenburg (RTB) was noted. Additional bolus of fentanyl $1 \mu \mathrm{g} / \mathrm{kg}$ was administered to maintain analgesia. Vecuronium $0.02 \mathrm{mg} / \mathrm{kg}$ was added when muscle relaxation was necessary. Maintenance of anesthesia was done with either sevoflurane 1-2\%, oxygen/nitrous oxide mixture (40/60)(Study Group) or sevoflurane 1-2\%, oxygen/air mixture(40/60) (Control Group). Intraabdominal pressure was maintained at 12 $\mathrm{mm}$ of $\mathrm{Hg}$. Sevoflurane was switched off at the time of application of skin stapler and nitrous oxide or air was switched off after reversing the effect of muscle relaxant. Oropharynx was softly suctioned and patients extubated.

The patients were then interviewed after one hour in postoperative ward for the presence or absence of sore throat.

\section{RESULTS}

The study was conducted in 128 patients, 64 in Study Group and 64 in Control Group.

Patients in both the groups were comparable in terms of age, gender, body mass index (BMI) and ASA physical status (Table 1). Similarly, there was no statistical difference among the groups in terms of attempts of intubation and duration of anesthesia (Table 2).

Patients were comparable in terms of volume of air injected to inflate the cuff (Table 3). Only four patients in Study Group and three in Control Group had baseline cuff pressure of $25 \mathrm{~cm}$ of $\mathrm{H} 2 \mathrm{O}$. Twenty nine patients in Study Group and twelve in Control Group had cuff pressure less than $25 \mathrm{~cm}$ of $\mathrm{H} 2 \mathrm{O}$ whereas thirty one patients in Study Group and forty nine in Control Group had cuff pressure more than $25 \mathrm{~cm}$ of $\mathrm{H} 2 \mathrm{O}$. There was no statistical difference in baseline cuff pressure between the groups (Table 3).

The cuff pressure in the study group was higher than in the control group at all times after creation of carboperitoneum at $15^{\text {th }}$ minute of anesthesia $(p<0.00)$ (Figure 2).35.93\% of patients in Study Group and $14.06 \%$ in Control Group complained of sore throat when enquired 1 hour post-surgery $(p=0.04)$.

\begin{tabular}{|c|c|c|c|}
\hline Parameter & $\begin{array}{r}\text { Study Group } \\
(\mathrm{n}=64)\end{array}$ & $\begin{array}{r}\text { Control } \\
\text { Group }(n=64)\end{array}$ & $\begin{array}{r}\mathrm{p} \\
\text { value }\end{array}$ \\
\hline Age (years) & $44.42 \pm 14.29$ & $40.66 \pm 16.2$ & 0.166 \\
\hline $\begin{array}{l}\text { Male/Female } \\
\text { (n) }\end{array}$ & $12 / 52$ & $16 / 48$ & 0.392 \\
\hline $\operatorname{BMI}\left(\mathrm{kg} / \mathrm{m}^{2}\right)$ & $24.69 \pm 3.11$ & $23.73 \pm 4.22$ & 0.149 \\
\hline ASA I/II (n) & $51 / 13$ & $48 / 16$ & 0.52 \\
\hline \multicolumn{4}{|c|}{$\begin{array}{l}\text { Data presented as mean } \pm S D . n=\text { number of patients; } S D= \\
\text { standard deviation; } B M I=\text { body mass index, } p \text { value } \leq 0.005 \\
\text { considered as significant }\end{array}$} \\
\hline \multicolumn{4}{|c|}{$\begin{array}{l}\text { Table } 2 \text {. Attempts of intubation, duration of anesthesia } \\
\text { and baseline cuff pressure. }\end{array}$} \\
\hline Parameter & $\begin{array}{l}\text { Study Group } \\
(n=64)\end{array}$ & $\begin{array}{l}\text { Control } \\
\text { Group }(n=64)\end{array}$ & $\underset{\text { value }}{\mathrm{p}}$ \\
\hline $\begin{array}{l}\text { Intubation } \\
\text { Attempt }\left(1^{\text {st }}\right. \\
\left./ 2^{\text {nd }}\right)\end{array}$ & $59 / 5$ & $58 / 6$ & 0.75 \\
\hline $\begin{array}{l}\text { Duration of } \\
\text { Anesthesia (min) }\end{array}$ & $72.27 \pm 17.18$ & $70 \pm 18.53$ & 0.47 \\
\hline $\begin{array}{l}\text { Baseline cuff } \\
\text { pressure }(\mathrm{cm} \\
\text { ofH2O) }\end{array}$ & $27.09 \pm 9.19$ & $29.44 \pm 6.54$ & 0.09 \\
\hline
\end{tabular}




\begin{tabular}{|c|c|c|c|}
\hline Parameter & $\begin{array}{l}\text { Study Group } \\
(n=64)\end{array}$ & $\begin{array}{l}\text { Control } \\
\text { Group }(n=64)\end{array}$ & $\underset{\text { value }}{\mathrm{P}}$ \\
\hline $\begin{array}{l}\text { Volume of air } \\
\text { (ml) }\end{array}$ & $7.66 \pm 1.38$ & $7.69 \pm 1.08$ & 0.88 \\
\hline $\begin{array}{l}\text { Baseline cuff } \\
\text { pressure }(\mathrm{cm} \\
\text { ofH2O) }\end{array}$ & $27.09 \pm 9.19$ & $29.44 \pm 6.54$ & 0.09 \\
\hline
\end{tabular}

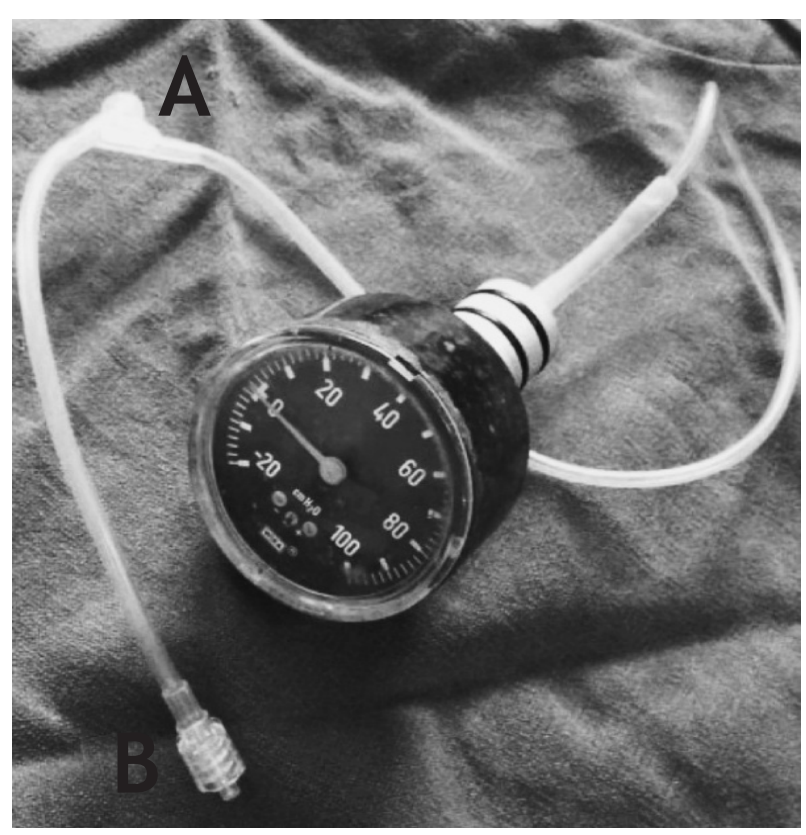

Figure 1. Aneroid Manometer used to measure endotracheal tube cuff pressure.

A: air injection port, B: port attaching to pilot balloon of endotracheal tube

\section{DISCUSSION}

In this study we noted gradual rise in ETT cuff pressure in both the study and control group after initiation of carboperitoneum. It can be explained by the increased intraabdominal pressure (IAP) which moves the diaphragm cephalad leading to rise in intra-thoracic pressure and peak airway pressure. ${ }^{3}$ Yildirim et al reported pneumoperitoneum and RTB increased cuff pressure during anesthetic maintenance with $1-2 \%$ sevoflurane and $66 \%$ air in oxygen. ${ }^{1}$ In the present study greater increase in cuff pressure in study group is probably due to combined effect of diffusion of nitrous oxide into the cuff and carboperitoneum as compared to that of the study group. There was no change in cuff pressure with the initiation of RTB position in both the groups. This can be explained by the fact that change in the cuff pressure is insignificant in RTB position as compared to that of trendelenburg position. This finding is supported by study conducted by Wu et al. ${ }^{4}$

Cuff pressure is not monitored routinely in anesthetic practice. Even short duration surgery can lead to postoperative airway complication when cuff pressure exceeds tracheal mucosal perfusion pressure. Seegobin et al evaluated endoscopically and confirmed that obstruction of mucosal blood flow occurred at a lateral wall pressure above $30 \mathrm{~cm} \mathrm{H} 20 .{ }^{5}$ ETT with high residual volume and low pressure is used to overcome damage caused by high pressure low volume ETT. Still the risk of tracheal mucosal injury persists when cuff is overinflated and concomitant diffusion of nitrous oxide from the anesthetic mixture. ${ }^{6}$ Thus, we emphasize the

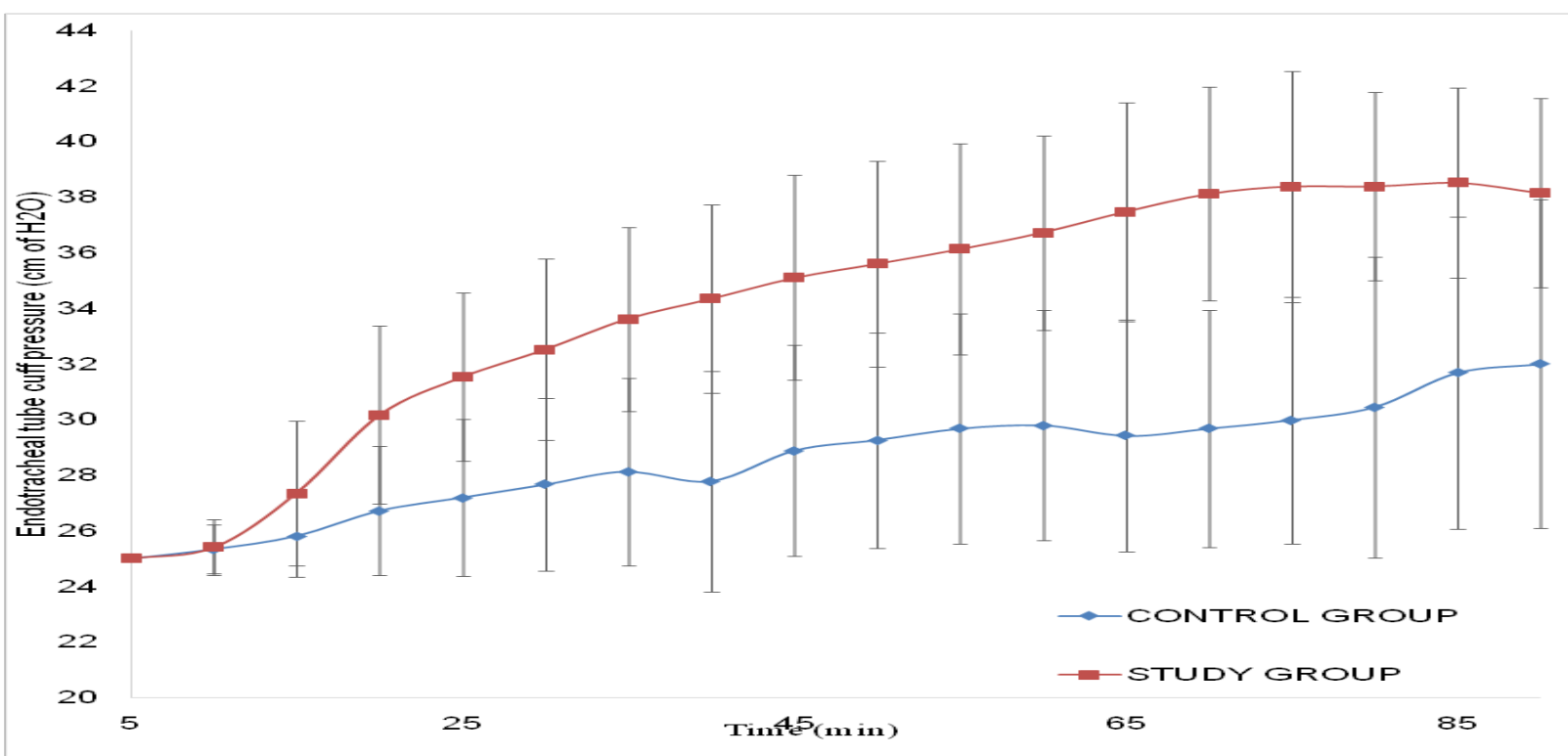

Figure 2. Cuff Pressure (mean $\pm \mathrm{sd})$ in each group. 
maintenance of cuff pressure within the therapeutic range of $20-30 \mathrm{~cm}$ of $\mathrm{H} 2 \mathrm{O}$ to avoid untoward airway complications as evidenced by past studies. ${ }^{7,8}$

Initially when the cuff was inflated and deemed to be normal by palpation technique only $47.6 \%$ of patient had cuff pressure within therapeutic range whereas $17 \%$ of the patients had cuff underinflated and $39 \%$ of the patients had cuff overinflated. This finding refutes the conventional way of palpating the pilot balloon and assuming the cuff pressure to be within therapeutic range as verified by past studies. ${ }^{8}$

The ETT cuff pressure is determining factor for postoperative sore throat. 9,10 When the cuff pressure increases beyond the tracheal mucosal perfusion pressure tracheal mucosal erosion occur. This factor has been attributed to post intubation sore throat. In the present study overall incidence of sore throat was $49.9 \%$. On reviewing the literature incidence of post-operative sore throat has been reported to range from 14.4 to $50 \% .{ }^{11}$ The higher incidence of sore throat observed in study group as compared to that of control group is due to use of nitrous oxide in study group.

We failed to monitor sore throat beyond 1 hour post operatively and we have not evaluated other airway complications as postoperative cough, hoarseness of voice and dysphagia. Further study is required to evaluate these factors.

\section{CONCLUSIONS}

The ETT cuff pressure rises significantly in laparoscopic cholecystectomy after creation of carboperitoneum. Increased cuff pressure might damage tracheal mucosa resulting in post-operative sore throat. Measurement of cuff pressure and maintaining it within $20-30 \mathrm{~cm}$ of $\mathrm{H} 2 \mathrm{O}$ must be a part of intraoperative monitoring. We recommend the use of cuff manometer routinely in all the cases to prevent untoward airway complications.

\section{REFERENCES}

1. Yildirim ZB, Uzunkoy A, Cigdem A, Ganidagli S, Ozgonul A. Changes in cuff pressure of endotracheal tube during laparoscopicand open abdominal surgery. Surg Endosc.2012;26:398-401. [Full Text]

2. Combes X,Schauvliege F, Olivier, Peyrouset O, Motamed C, Kirov K et al.Intracuff Pressure and Tracheal Morbidity: Influence of Filling Cuff with Saline during Nitrous Oxide Anesthesiology. 2001;95:120-4.[Full Text]
3. Casati A, Valentini G, Ferrari S, Senatore R, Zangrillo A, Torri G. Cardiorespiratory changes during gynaecological laparoscopyby abdominal wall elevation: comparison with carbon dioxide pneumoperitoneum. Br J Anaesth. 1997;78:51-4.[Full Text]

4. Wu CY, Yeh YC, Wang MC, Lai CH, Fan SZ. Changes in endotracheal tube cuff pressure during laparoscopic surgery in head-up or head-down position. BMC Anesthesiol. 2014;14:75. [Full Text]

5. Seegobin RD, Hasselt GL. Endotracheal cuff pressure and tracheal mucosal blood flow: endoscopic study of effects offour large volume cuffs. Br Med J. 1984;288:965-8. [Full Text]

6. Leigh JM, Maynard JP.Pressure on the tracheal mucosa from cuffed tubes. Br Med J.1979;1(6172):1173-4. [Full $\underline{\text { Text] }}$

7. SenguptaP, SesslerD, Maglinger P,Wells S, Vogt A,Durrani $\mathrm{J}$ et al.Endotracheal tube cuff pressure in three hospitals, and the volume required to produce an appropriate cuff pressure.BMC Anesthesiol. 2004;4:8. [PubMed]

8. Fernandez R, Blanch L, Mancebo J, Bonsoms N, Artigas A. Endotracheal tube cuff pressure assessment: pitfalls of finger estimation and need for objective measurement. Crit Care Med.1990:18;1423-6. [PubMed]

9. Suzuki N, Kooguchi K, Mizobe T, Hirose M, Takano Y, Tanaka Y. Postoperative hoarseness and sore throat after tracheal intubation: Effect of a low intracuff pressure of endotracheal tube and the usefulness of cuff pressure indicator. Masui. 1999;48:1091-5. [PubMed]

10. Mandoe H, Nikolasjen L, Lintrup U, Jespen D, Molgaard J. Sore throat after endotracheal intubation. Anesth Analg. 1992; 74:897-900. [PubMed]

11. McHardy FE, Chung F. Postoperative sore throat: cause, prevention and treatment. Anaesthesia.1999;54:444-53. [PubMed] 